\title{
НОВЫЕ ХИТИНОЗОИ РОДА CONOCHITINA ИЗ ВЕНЛОКА ЭСТОНИИ
}

Настоящая статья представляет собой часть результатов исследований автора по таксономии и зональному распределению венлокских хитинозой Эстонии (Нестор, 1982б), которые до сих пор специально не изучались и не описывались. Сведения о присутствии в венлокских отложениях Эстонии нескольких видов хитинозой, приведенные в работах А. Эйзенака (Eisenack, 1964, 1968, 1970), Р. Мянниля (1970) и В. Нестор (1982a), не сопровождались их описанием. В то же время таксономически детально изучены и описаны хитинозои о-ва Готланд (Laufeld, 1974; Eisenack, 1964; Taugourdeau, Jekhowsky, 1964). Хорошая изученность готландских хитинозой и наличие многих общих форм в венлоке обоих регионов значительно способствуют изучению эстонского материала. Описанные нами новые конохитины (5 видов) встречаются в основном в верхней половине венлока, точнее, в верхах парамаяской свиты и в сырвеской свите, представленных мергелями и глинистыми известняками. Эти отложения вскрыты буровыми скважинами в Южно-Эстонском и Западно-Латвийском структурно-фациальных районах (Кальо, Юргенсон, 1977). В районе выходов они, вероятно, замещены относительно мелководными сгустковыми, сортированно-детритовыми и биогермными известняками яагарахуской свиты (Нестор, 1982a), не содержащими хитинозои. В связи с этим возраст парамаяской свиты в данной статье рассматривается условно как нерасчлененно яаниско-яагарахуский $\left(\mathrm{J}_{1} \mathrm{~J}_{2}\right)$. В статье приведены предварительные данные о распространении рассматриваемых видов и в разрезах скважин Колка и Вентспилс Западной Латвии.

Автор признателен Р. Мяннилю и Х. Нестору за полезные советы. Микрофотографии выполнены на сканирующем электронном микроскопе фирмы «Акаси» сотрудником института Е. Климовым.

Материал хранится в Институте геологии АН ЭССР.

\section{Род Conochitina Eisenack, 1931}

Conochitina emmastensis sp. $\mathrm{n}$.

Табл. I, фиг. $1-3$, рис. 1

Н а з вание вида от названия скв. Эммасте (о. Хийумаа), откуда происходит голотип.

Голоти п. Ch 180/1204, скв. Эммасте, гл. 33,8 м, адавереский горизонт. Д и агно 3. Везикула субконическая до субцилиндрической, с широкой камерой. Короткая шейка сравнительно узкая. Базальный край закругленный. Основание слабо вогнутое или выпуклое, снабженное мукроном.

О писани е. Форма камеры изменчивая. Обычно стенки везикулы прямые, с наибольшей шириной у базального края, но иногда встре- 

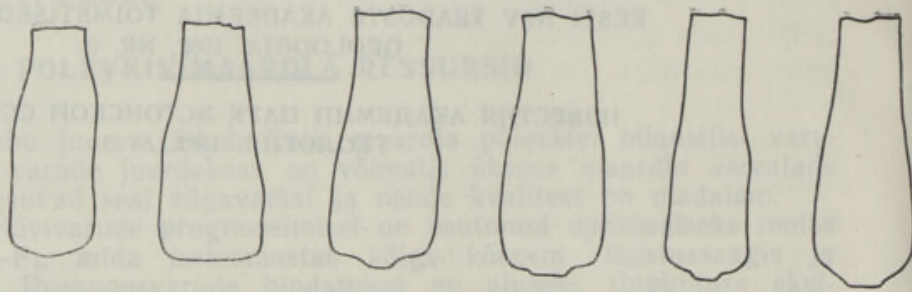

Рис. 1. Изменчивость внешней формы везикулы Conochitina emmastensis из скв. Икла (гл. 309,2 м); $110 \times$.

чаются и везикулы со слабовыпуклыми стенками. Везикулы у этого вида имеют обычно характерную форму частичной деформации боковых стенок (см. табл. 1, фиг. 2-3), наблюдается и частое погружение мукрона. Мукрон обычно широкий и низкий. Иногда развит и каллус. Флексура слабая или отсутствует. Внешняя поверхность везикулы гладкая. У стьевой край обычно расширяющийся, устье ровное.

Р а з меры (в микронах): длина везикулы 240-380 (у голотипа 250), максимальная ширина $85-130$ (у голотипа 100), минимальная ширина шейки 55-85 (у голотипа 75).

С р а внение и за мечания. Данный вид несколько похож на Conochitina tuba Eisenack, но у C. emmastensis везикула длиннее, камера шире, шейка более узкая и обычно расширяющаяся в направление устья.

По сравнению с $C$. proboscifera Eisenack $C$. emmastensis короче, камера и мукрон более широкие и стенка везикулы значительно тоньше.

Р аспростанение. Вид встречается в. адавереском горизонте и в низах яаниского горизонта. По граптолитовой шкале этот интервал соответствует зонам от sedgwickii до murchisoni (ом. Кальо, 1970).

В разрезах буровых скважин C. emmastensis встречается спорадически, особенно в разрезах скважин о-ва Сааремаа. Интервалы распространения: скв. Варбла, гл. $132-160$ м; скв. Кирикукюла, гл. $1-49$ м; скв. Эммасте, гл. 33-44 м; скв. Икла, гл. 305-312 $\mu^{*}$; скв. Рухну, гл. 454-489 $м$; скв. Пулли II, гл. 27-59 м; скв. Охесааре, гл. 343-367 ; скв. Тылла, гл. $125-127$ м.

М а т е и ал: более 300 экземпляров.

\section{Conochitina cribrosa sp. n.}

Табл. I, фиг. 4-5; Табл. II, фиг. $1-3$

Наз вание вида (cribrosa (лат.) - решетчатый) по решеткообразной орнаментации внешней поверхности везикулы.

Г олоти п. Ch 145/1609, скв. Икла, гл. 185,5 м, яагарахуский горизонт.

Ди агноз. Везикула коническая до субконической, с прямыми боковыми стенками и закругленным базальным краем, и с тонкой решеткообразной орнаментацией внешней поверхности.

О пи с а и е. Внешняя форма везикулы изменчивая. Основание может быть вогнутое, плоское или слабовыпуклое, обычно без мукрона, с базальным скаром в центре, иногда с мукроном разной формы и величины. Боковые стенки обычно прямые, расширяющиеся около устья, но встречаются и экземпляры со слабовыпуклыми стенками. Базальный край широко закругленный. Флексура не развита. Устьевой край ровный.

* Разрез скв. Икла исследован частично. 
Везикула имеет характерную тонкую решеткообразную орнаментацию (перидерму), которая крупнее в области базального края и мельче в области устья. Орнаментация состоит из мелких неправильных стержней, прикрепленных к поверхности везикулы (к эксодерме) и составляющих неправильные петлевидные образования. Устьевой край и середина основания лишены орнаментации.

Р а з м еры (в микронах): длина везикулы 160-280 (у голотипа 240), максимальная ширина 70-100 (у голотипа 90), минимальная ширина 50-70 (у голотипа 65). Соотношение длины везикулы к максимальной ширине колеблется от $2: 1$ до $3: 1$. Диаметр отдельных петель решетчатой орнаментации в среднем $1-3 \mu$.

C р а внение и замеч ания. Conochitina cribrosa встречается вместе c C. $t u b a$ и похож на него по внешней форме. Существенно, что типичные формы C. tuba имеют мукрон, а C. cribrosa имеет обычно вогнутое основание. Сохранность орнаментации у C. cribrosa различная. Иногда часть стержней сломана или изношена и на поверхности могут сохраняться лишь неправильные мелкие шипики. А. Эйзенак при описании C. tuba (Eisenack, 1962, 295) включил в состав этого вида и экземпляры с мелкими шипиками максимальной высоты до $2 \mu$. Не исключено, что это были экземпляры $C$. cribrosa c частично сохранившейся орнаментацией. Следуя С. Лауфельду (Laufeld, 1974, 73), мы относим к C. tuba только экземпляры с гладкой внешней поверхностью.

Р аспростр анение и м а те ри ал. Conochitina cribrosa встречается в верхней половине сырвеской свиты яагарахуского горизонта. По граптолитовой шкале диапазон распространения этого вида охватывает верхи зоны lundgreni и зону nassa. Вспречен в скв. Охесааре, гл. 161192 м; скв. Рухну, гл. 288-325 м; скв. Икла, гл. 183-205 м; скв. Колка, гл. 425-466 м. Имеется более 300 экземпляров.

\section{Conochitina fortis sp. n.}

Табл. III, фиг. 1-4

Н а з вание вида (fortis (лат.) - сильный, здоровый) ссылается на кряжистую фигуру везикул этого вида.

Г ол оти п. Ch 170/1592, скв. Охесааре, гл. 200,0 м, яагарахуский горизонт.

Д и а г о з. Везикула субцилиндрическая, с прямыми или слабовыпуклыми боковыми стенками пузатой камеры, которая имеет широко закругленный базальный край и крупный концентрически штрихованный мукрон в середине слабовыпуклого основания.

О пи с ан и е. У субцилиндрической везикулы флексура и плечо не развиты или развиты слабо. Шейка широкая, иногда отличима от камеры, иногда нет. Встречаются и экземпляры со слабо сжатыми боковыми стенками в нижней трети камеры. Широкий конический мукрон имеет характерную концентрическую штриховку. Устье ровное. Внешняя повехрность везикулы гладкая.

Р а з меры (в микронах): длина везикулы 200-380 (у голотипа 270), максимальная ширина $85-110$ (у голотипа 110), минимальная ширина $55-75$ (у голотипа 70 ).

C p авнение и зам еч ания. Conochitina fortis встречается совместно c C. cf. pachycephala и C. tuba и, возможно, филогенетически связан с этими видами. C. fortis имеет субцилиндрическую везикулу с более или менее параллельными стенками камеры (у сплюснутых экземпляров 
$a$
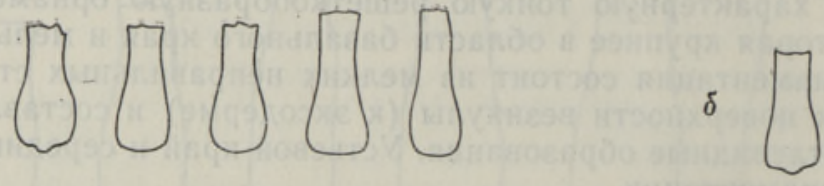
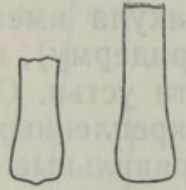

Рис. 2. Изменчивость внешней формы везикулы Conochitina subcyatha. $a$ - из скв. Рухну (гл. $333,0, \mu), 6$ - из скв. Охесааре

(гл. 216,1 м); $110 \times$.

стенки выпуклые), у C. tuba и $C$. pachycephala везикулы конические или субконические, кроме того, C. tuba может встречаться и без мукрона (см. Eisenack, 1962, рис. 2).

По внешней форме $C$. fortis несколько похож на $C$. proboscifera $\mathrm{f}$. truncata (см. Laufeld, 1974, рис. 34-D), но у последнего мукрон меньше, a соотношение длины к ширине больше (1:3-5, у C. fortis $1: 2-3)$ и стенка везикулы значительно толще (см. Laufeld, 1974, 70).

Р а спростр анен и е. Conochitina fortis встречается в верхах венлока, в пределах верхов парамаяской и низов сырвеской свиты в разрезах Южно-Эстонского и Западно-Латвийского структурно-фациальных районов. По граптолитовой шкале этот интервал грубо соответствует зоне lundgreni.

Установлен в скв. Охесааре, гл. 191-246 м; скв. Рухну, гл. 325-356 скв. Икла, гл. 206-245 м; скв. Колка, гл. 452-485 м; скв. Вентспилс, гл. $710-726 \mu$.

В коллекции более 200 экземпляров.

Conochitina linearistriata sp. n.

Табл. III, фиг. $5-8$

Н а з в а н и е вид а (linearistriata (лат.) - линейно заштрихованный) охарактеризует тонкую орнаментацию внешней поверхности везикулы. Г ол о ти п. Ch 174/1590, скв. Охесааре, гл. 206,0 м, верхняя часть парамаяской свиты яагарахуского (?) возраста.

Д и агно з. Везикула субконическая, с вогнутым основанием и широко закругленным базальным краем и со слабым прижимом боковых стенок непосредственно выше базального края. Внешняя поверхность везикулы несет тонкую линейно-штриховатую орнаментацию.

О пи с а н ие. Боковые стенки везикулы более или менее прямые, иногда слабо вогнутые или выпуклые. Прижим боковых стенок наблюдается или отсутствует. Обособленная шейка и флексура отсутствуют. В центре

\section{ТАБЛИЦА I}

Фиг. 1-3. Conochitina emmastensis sp. n. 1 - экз. Ch 104/1734, скв. Рухну, гл. 457,45 м, J $;$; $\times 250.2$ - голотип Ch $180 / 1204$, скв. Эммасте, гл. 33.8 м, H; $\times 250$. $3-$ экз. Ch $181 / 1385$, скв. Варбла, гл. 159,55 м, Н; $3 a-\times 250,36-\times 660$.

Фиг. 4-5. Conochitina cribrosa sp. n., J. 4 - экз. Ch 177/1598, скв. Охесаape, гл. $188,2 \mu, 4 a-\times 310,46-\times 2040.5-$ голотип Ch $145 / 1609$, скв. Икла, гл. $185,5 м$, $5 a-\times 310,56-\times 4900$.

ТАБЛИЦА II

Фиг. 1--3. Conochitina cribrosa sp. п., Ј $\mathrm{J}_{2} .1-$ экз. Ch 142/1599, скв. Охесаape, гл. $185,8 \mu, 1 a-\times 250,16-\times 660.2-$ экз. Ch $178 / 1598$, скв. Охесааре, гл. 188,2 $\mu$, $2 a-\times 310,26-\times 2040.3-$ - 2 к. Ch 179/1606, скв. Охесааре, гл. 166,9 м, $3 a-\times 310$, $36-\times 1360$. 
ТАБЛИЦА I
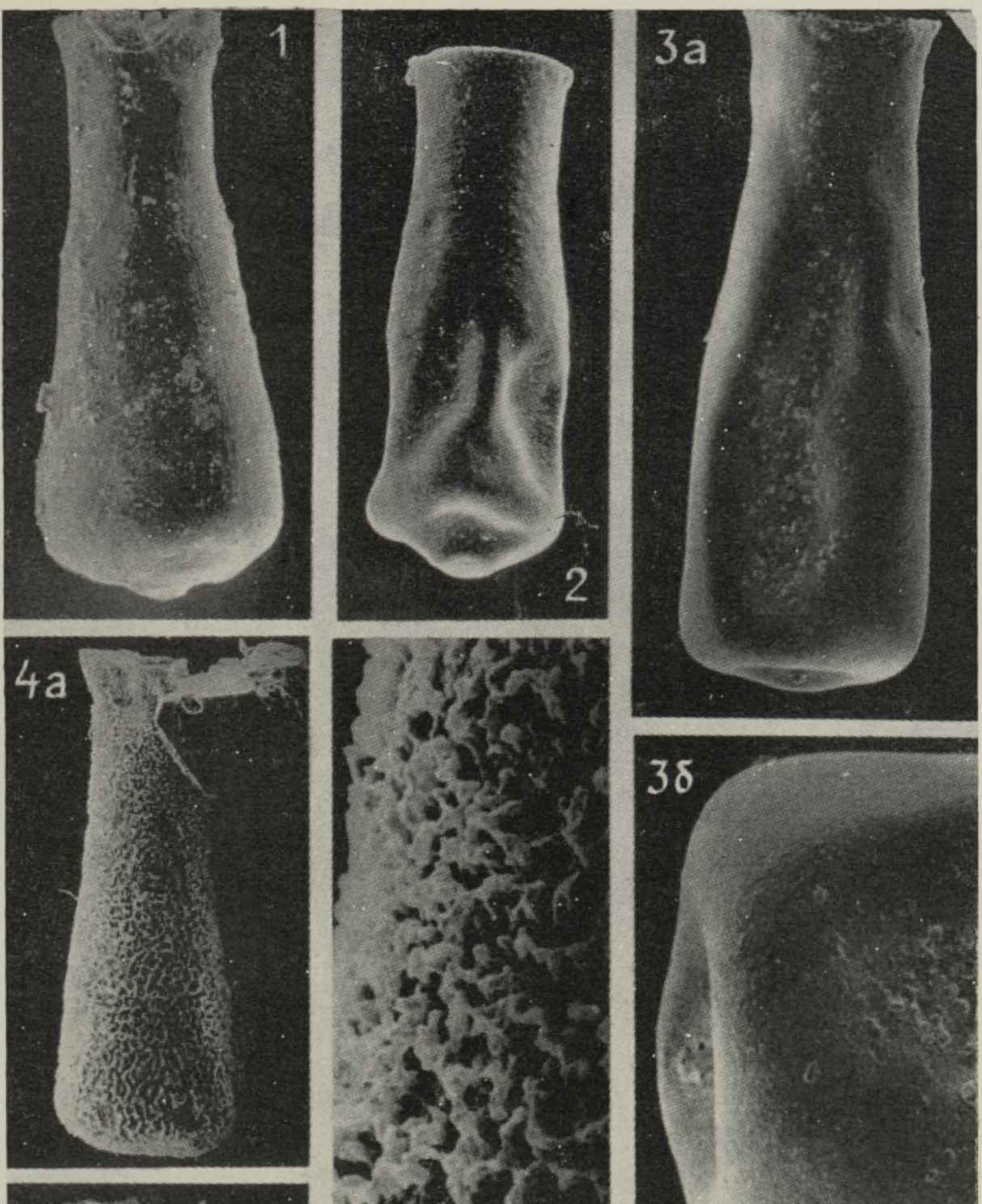

$4: 5 a$

ind 1
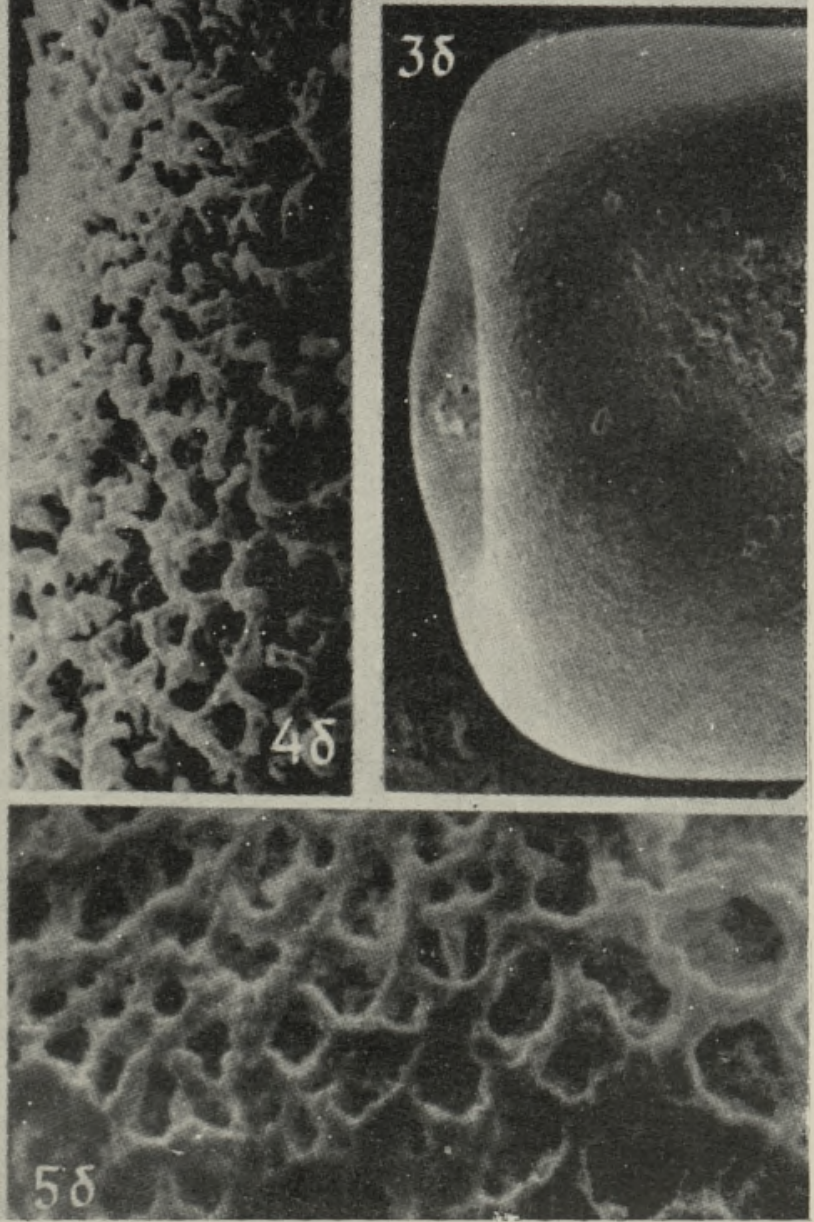

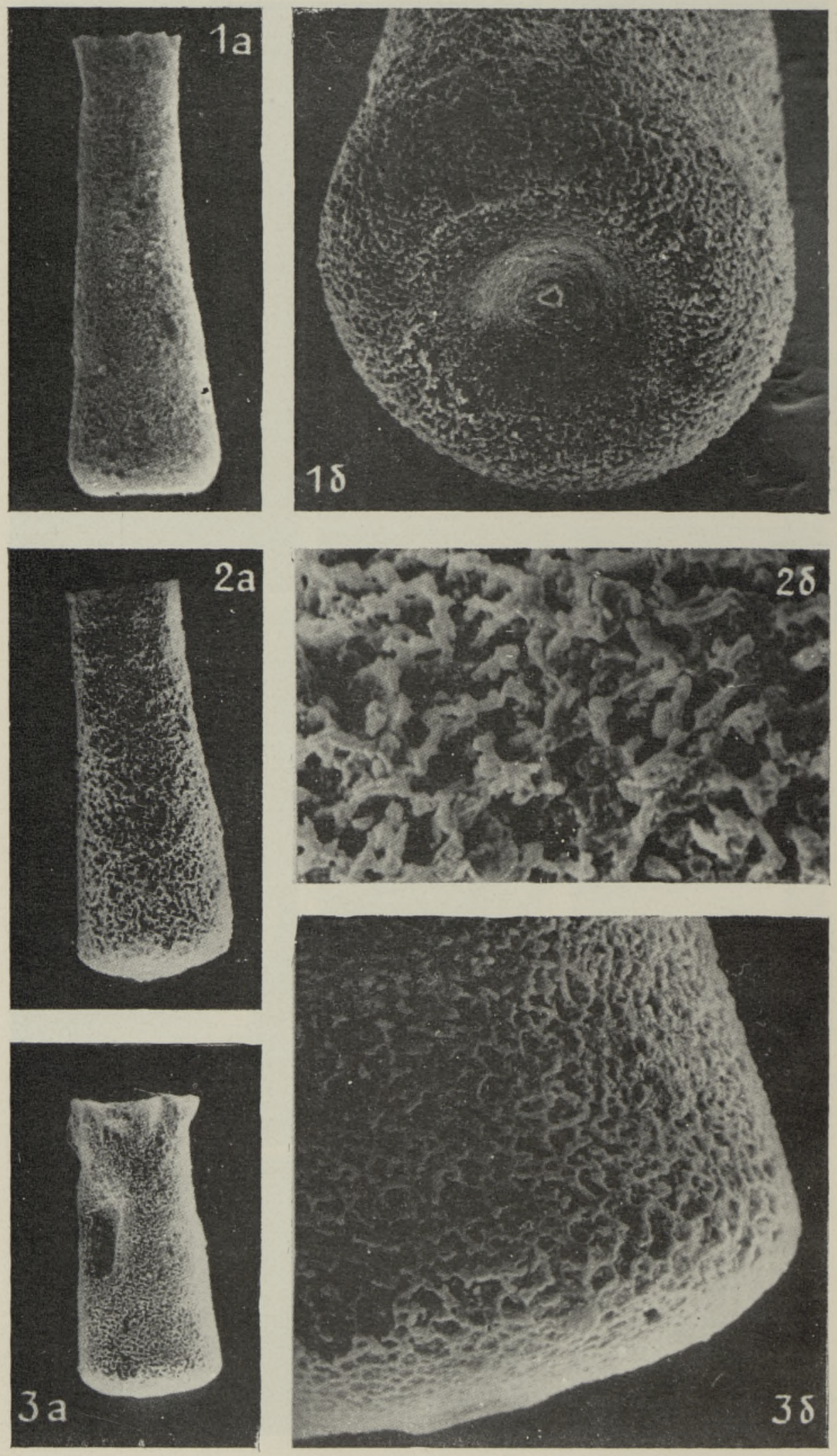

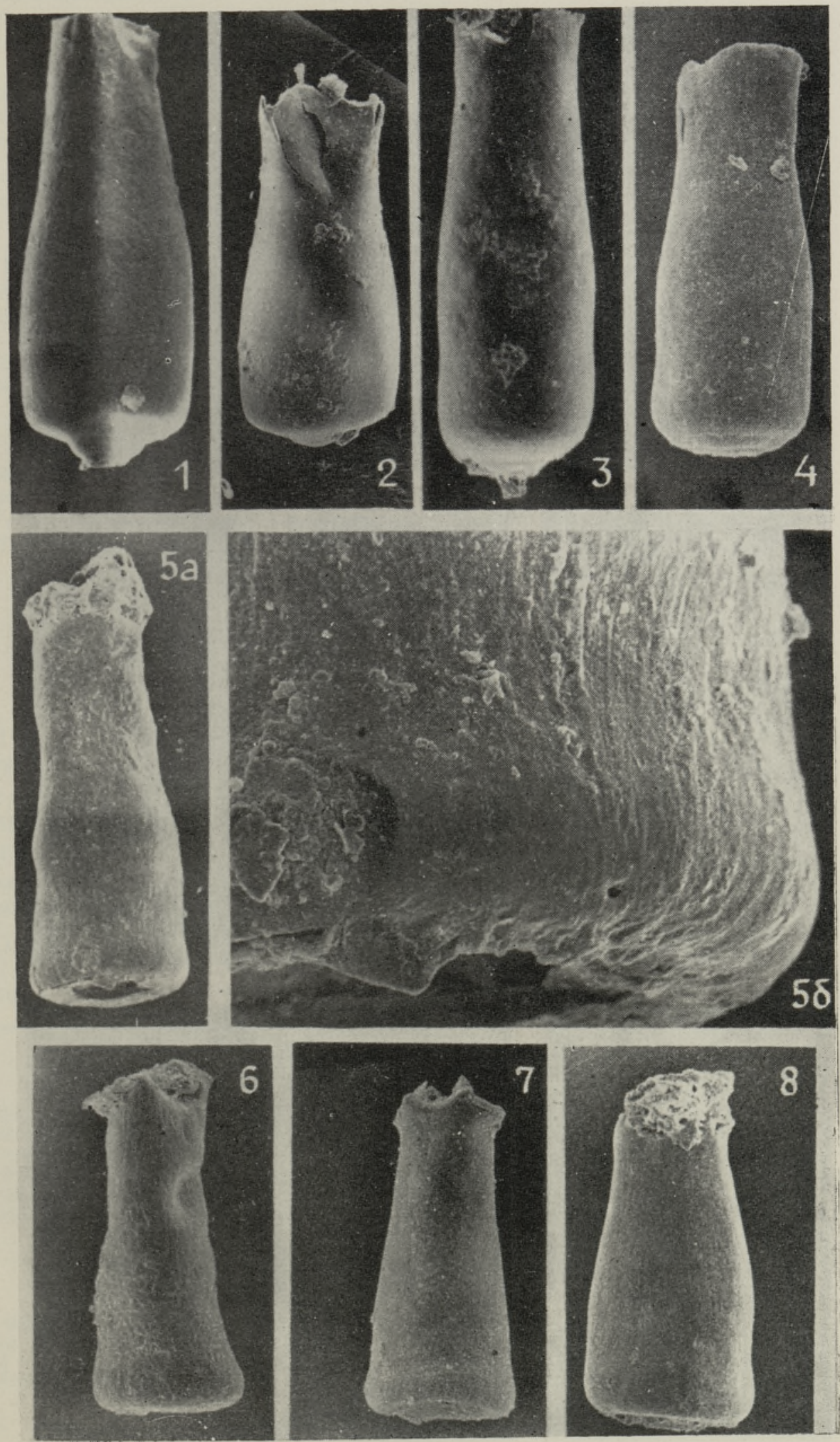
ТАБЛИЦА IV
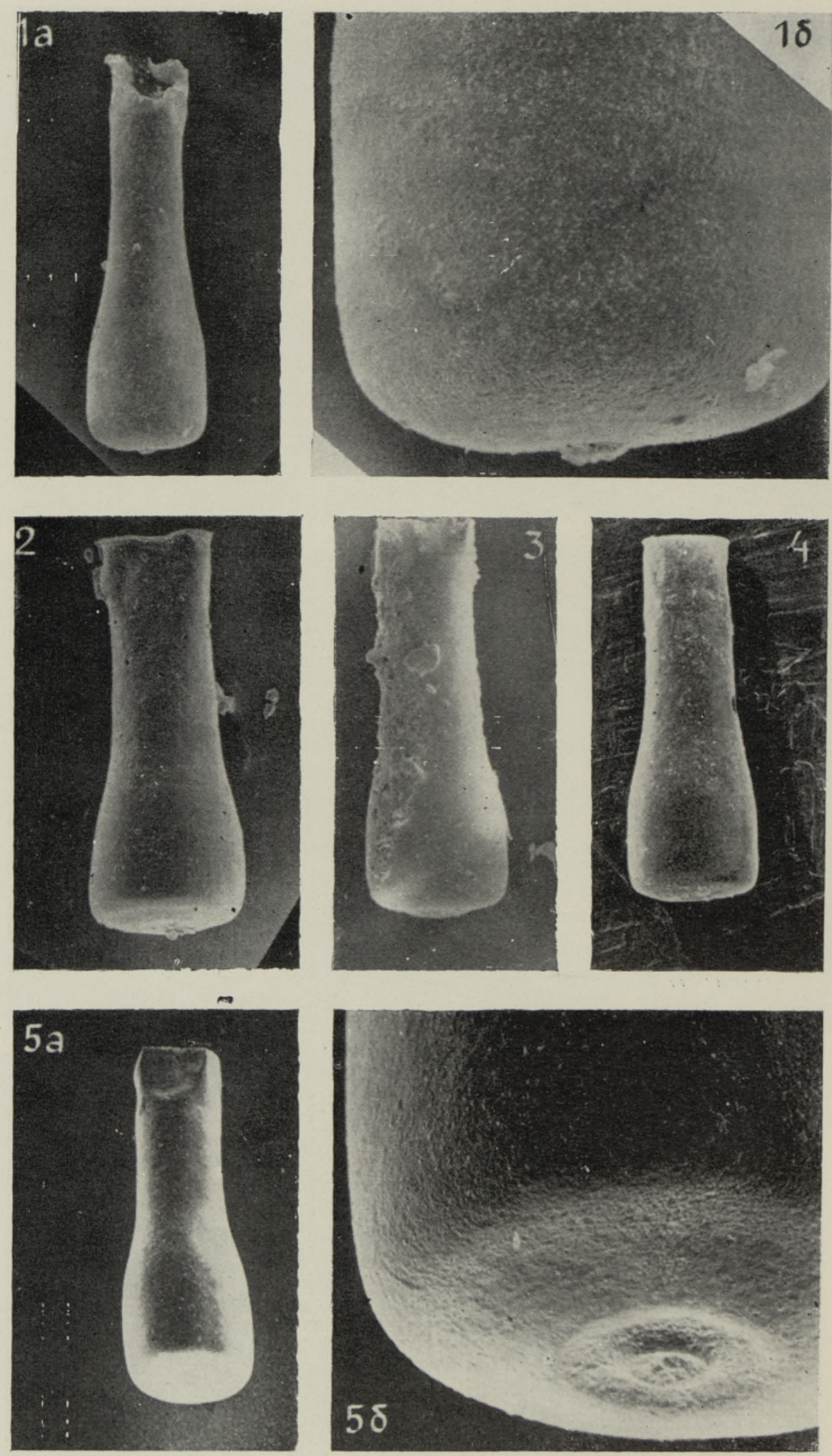
более или менее вогнутого основания находится базальный скар. Везикула наименьшей ширины непосредственно ниже устья. Устьевой край расширяется резко, напоминая оборку.

Внешняя поверхность везикулы обычно вертикально тонколинейно заштрихована. Орнаментация - наиболее четко развита у базального края. она очень тонкая, ее трудно проследить, особенно при сплюснутом материале.

Р а зм еры. (в микронах): длина везикулы 150-270 (у голотипа 175). максимальная ширина $80-100$ (у голотипа 85), минимальная ширина $55-70$ (у голотипа 60).

С равнение и замечания. Conochitina linearistriata встречается совместно с $C$ tuba, $C$. cf. pachycephala и $C$. subcyatha, отличается характерной орнаментацией и некоторыми другими признаками. C. tuba и C. subcyatha имеют мукрон и прямые боковые стенки, без сжатия, устьевая часть везикулы у них расширяется мало. C. pachycephala длиннее. имеет хорошоразвитую шейку и его основание плоское или выпуклое. с мукроном.

$\mathrm{P}$ асп постр анение. Conochitina linearistriata встречается в верхах венлока в интервале разреза, также соответствующей приблизительно зоне lundgreni. Обнаружен в разрезе скв. Охесааре, гл. 192-248 $м$; скв. Рухну, гл. $331-355$ м; скв. Икла, гл. 202-245 м; скв. Колка, гл. 440$475 \mu$.

М а тери ал представлен примерно 200 экземплярами.

\section{Conochitina subcyatha sp. $\mathrm{n}$.}

Табл. IV, фиг. $1-5$; рис. 2

Н аз вание вида (subcyatha (греч.) - близкая к губке) характеризует форму везикулы.

Гол о ти п. Ch 167/977, скв. Охесааре, гл. 218,05 м, верхняя часть парамаяской свиты яагарахуского (?) возраста.

Д и а гн оз. Везикула субконическая до субцилиндрической, с плоским или слабовогнутым основанием, с ясно выделяющимися камерой и шейкой, которая составляет $1 / 2$ или $2 / 3$ всей длины везикулы.

О пи с а н и е. Своеобразие вида - наличие относительно длинной шейки и короткой камеры. Флексура и плечо в большей или меньшей мере развиты, иногда оно может и отсутствовать. Боковые стенки камеры прямые

\section{ТАБЛИЦА III}

Фиг. 1-4. Conochitina fortis sp. n., $\mathrm{J}_{1} \mathrm{~J}_{2}, 1-$ экз. Ch 170/1592, скв. Охесааре, гл. $200,0 \mu ; \times 250,2$ - экз. Ch $171 / 1773$, скв. Рухну, гл. $333 \mu ; \times 310.3$-- экз. Ch $172 / 1591$, скв. Oхесаape, гл. 202,8 $м ; \times 310.4$ - экз. Ch 173/1585, скв. Охесааре, гл. 223,65 м; Х250. Фиг. 5-8. Conochitina linearistriata sp. п., $\mathrm{J}_{1} \mathrm{~J}_{2} .5$ - голотип Ch 174/1590. скв. Охесааре, гл. 206 м, $5 a-\times 250,56-\times 2040.6-$ экз. Ch $175 / 1581$, скв. Охесааре, гл. $243 \mu ; \times 310.7$ - экз. Ch $139 / 1585$, скв. Охесааре, гл. $223,65 \mu ; \times 310.8-$ экз. Сh $176 / 1590$, скв. Oхесаape, гл. $206 \mu ; \times 250$.

\section{ТАБЛИЦА IV}

Фиг. 1-5. Conochitina subcyatha sp. n., $\mathrm{J}_{1} \mathrm{~J}_{2} .1$ - голотип Ch 167/977, скв. Oхесаape, гл. 218,05 м. $1 a-\times 310,16-\times 1360.2-$ экз. Ch $168 / 773$, скв. Рухну, гл. 333 м; $\times 310$. 3 - экз. Ch 135/1587, скв. Охесааре, гл. 225,05 $\mu$; $\times 250.4$ - экз. Сh 136/1770, скв. Рухну, гл, 341,5 ; $\times 250$. 5 - экз. Ch $169 / 1765$, скв. Рухну, гл, $356 \mu, 5 a-\times 250$, $56-\times 1360$ 
или слабо выпуклые. Базальный край обычно хорошо развит, в большей или меньшей мере закругленный. Основание обычно плоское, с небольшим мукроном в центре. Иногда встречаются везикулы с погруженным мукроном или без мукрона, а также с низким каллусом.

В направлении устья шейка расширяется. Устье ровное. Внешняя поверхность везнкулы гладкая.

Р а з меры (в микронах): длина везикулы 155-300 (у голотипа 210), максимальная ширина камеры $65-120$ (у голотипа 65), минимальная ширина шейки 35-55 (у голотипа 40).

С равнение и за мечания. Данный вид встречается совместно с Conochitina tuba, с которым он близок по величине, однако у $C$. tuba флексура не развита или развита очень слабо.

Oт C. claviformis новый вид отличается более короткой везикулой и более развитой флексурой (см. Eisenack, 1968, 159). C. armillata (см. Taugourdeau, Jekhowsky, 1960) имеет выпуклые основание и боковые стенки.

Р аспространени е. C. subcyatha встречается в верхах венлока, в буровых скважинах Южно-Әстонского и Западно-Латвийского структурно-фациальных районов. По граптолитовой шкале интервал его распространения грубо соответствует нижней половине зоны lundgreni. Bстречается в скв. Охесааре, гл. 198-226 м; скв. Рухну, гл. 329-357 м; скв. Икла, гл. 219-230 м; скв. Вентспилс, гл. 714-722 м и скв. Колка, гл. $452-471 \mu$.

В разрезах Вентспилс, гл. 643-660 м (зона nilssoni), и Колка, гл. 393-400 м, встречаются формы, которые можно определить как $C$. cf. subcyatha.

М а те р и ал: 300 экземпляров.

\section{Л И Т Е РА Т У Р А}

К а л ь о Д. Граптолиты. - В кн.: Силур Эстонин. Таллин, 1970, 179-185.

К а ль о Д., Ю р ге н с о н Э. А. Фациальная зональность силура Прибалтики, - В кн.: Фации и фауна снлура Прибалтики. Таллин, 1977, 122-144.

М ян н и ль Р. М. Кислотоустойчивые микрофоссилии. - В кн.: Силур Эстонии. Таллин, 1970, 176-179.

Нестор В. Зональное распределение хитинозой в яаниском горизонте (венлок Эстонии) и проблема его границ. - В кн.: Стратиграфия древнепалеозойских отложений Прнбалтики. Таллин, 1982а.

Н естор В. Зональные комплексы хитинозой венлока Эстонин. - В кн.: Сообщества и биозоны в силуре Прибалтики. Таллин, 19826.

E isena ck, A. Neotypen baltischer Silur-Chitinozoen und neue Arten. - N. Jb. Geol. Pal. Abh., 1962, 114, 291-316.

E i s en a ck, A. Mikrofossilien aus dem Silur Gotlands. Chitinozoen. - N. Jb. Geol. Pal. Abh., 1964, 120, 308-342.

Eisenack, A. Uber Chitinozoen des baltischen Gebietes. - Palaeontographica, 1968, 131, Abt. A., 137-198.

Eisenack, A. Mikrofossilien aus dem Silur Estlands und der Insel Osel. - Geol. Fören. Stockholm Förh., 1970, 92, 302-322.

L a u f e 1 d, S. Silurian Chitinozoa from Gotland. - Fossils and Strata, 1974, 5.

T a u gourdeau, P., De J e khowsky, P. Répartition et description des chitinozoaires Siluro-Devoniens de quelques sondages de la S. N. REPAL au Sahara. - Rev. Inst. Franc. Petrole Ann. Combust. Liquides, 1960, 15, $1199-1260$.

T a u gourdeau, P., De Jekhowsky, P. Chitinozoaires Siluriens de Gotland: Comparaison avec les formes sahariennes. - Rev. Inst. Franc. Petrole Ann. Combust Liquides, $1964,19,845-871$. 
UUED CONOCHITINA LIIGID EESTI UENLOKIST

Artiklis on esitatud vije kitinozoaliigi esmaskirjeldus ja levik jaani ja jaagarahu lademes.

\section{Viiu NESTOR}

\section{NEW WENLOCKIAN SPECIES OF CONOCHITINA FROM ESTONIA}

The present paper is a part of the results of the author's studies on the taxonomy and zonal distribution of Estonian Wenlockian chitinozoans. Five new species are described, out of which Conochitina emmastensis is found in the Upper Llandoverian and Lower Wenlockian rocks, corresponding to the interval of the graptolite zones from sedgwickii to murchisoni. The others - C. cribrosa, C. fortis, C. linearistriata and $C$. subcyatha come from Upper Wenlockian beds mainly corresponding to the lundgreni zone. These species occur only in the upper part of the Paramaja Formation and in the Sõrve Formation, in marls and clayey limestones, which in the outcrop area are laterally replaced by biohermal and other nearshore limestones of the Jaagarahu Formation not containing chitinozoans.

\section{Conochitina cribrosa sp. $\mathrm{n}$.}

Conical to subconical vesicle with straight flanks. The base from slightly concave to slightly convex, with a scar and a broadly rounded basal edge. The flexure is weak or undeveloped. Sometimes the central part of the base is provided with a short mucron. The vesicle wall is covered by very fine, net-like spongy ornamentation, which is coarser in the aboral part of the vesicle and finer in the oral one. The aperture and the central part of the base lack ornamentation.

\section{Conochitina emmastensis sp. $\mathrm{n}$.}

Subcylindrical to subconical vesicle with swollen wide chamber and flanks, which have the usually characteristic form of deformation (PI. I, Figs 2, 3). The base is slightly concave or convex and the basal edge rounded. The base is provided with a short and wide mucron. The neck relatively short, less than one-third of total length. The flexure and shoulder broadly rounded or lacking. The vesicle wall smooth.

\section{Conochitina fortis sp. $\mathrm{n}$.}

Subcylindrical vesicle with straight or slightly convex flanks and broadly rounded basal edge. The base slightly convex and provided with a wide, concentrically striated cone-like mucron. The flexure and shoulder weakly or not developed. The vesicle wall smooth.

\section{Conochitina linearistriata sp. n.}

Subconical vesicle with concave base and broadly rounded basal edge. The flanks more or less straight and commonly with slight constriction oralward of the basal edge. The neck is weakly differentiated from the chamber. Oral part of the vesicle considerably widened. A scar is present. The vesicle wall, especially at the basal edge, is longitudinally very finely striped.

\section{Conochitina subsyatha sp. $\mathrm{n}$.}

Subconical to subcylindrical vesicle with flat or slightly concave base and broadly rounded flexure. The long neck forms a half to two-thirds of the total length. The basal edge rounded, the base commonly provided with low callus and small mucron. The vesicle wall smooth. 